\title{
Selective serotonergic excitation of callosal projection neurons
}

\author{
Daniel Avesar ${ }^{1,2}$ and Allan T. Gulledge ${ }^{1,2 *}$ \\ ' Department of Physiology and Neurobiology, Dartmouth Medical School, Lebanon, NH, USA \\ 2 Program in Experimental and Molecular Medicine, Dartmouth College, Hanover, NH 03755, USA
}

\author{
Edited by: \\ Yoshiyuki Kubota, National Institute \\ for Physiological Sciences, Japan \\ Reviewed by: \\ Daniel Johnston, University of \\ Texas, USA \\ Bob C. Foehring, University of \\ Tennessee, USA \\ ${ }^{*}$ Correspondence: \\ Allan T. Gulledge, Department of \\ Physiology and Neurobiology, \\ Dartmouth Medical School, One \\ Medical Center Drive, DHMC, \\ Borwell 704E, Lebanon 03756, \\ NH, USA. \\ e-mail: allan.gulledge@ \\ dartmouth.edu
}

Serotonin (5-HT) acting as a neurotransmitter in the cerebral cortex is critical for cognitive function, yet how 5-HT regulates information processing in cortical circuits is not well understood. We tested the serotonergic responsiveness of layer 5 pyramidal neurons (L5PNs) in the mouse medial prefrontal cortex (mPFC), and found three distinct response types: long-lasting 5- $\mathrm{HT}_{1 \mathrm{~A}}(1 \mathrm{~A})$ receptor-dependent inhibitory responses $(84 \%$ of L5PNs), $5-H_{2}$ (2A) receptor-dependent excitatory responses (9\%), and biphasic responses in which $2 \mathrm{~A}$-dependent excitation followed brief inhibition (5\%). Relative to 5-HT-inhibited neurons, those excited by $5-\mathrm{HT}$ had physiological properties characteristic of callosal/commissural (COM) neurons that project to the contralateral cortex. We tested whether serotonergic responses in cortical pyramidal neurons are correlated with their axonal projection pattern using retrograde fluorescent labeling of COM and corticopontine-projecting (CPn) neurons. 5-HT generated excitatory or biphasic responses in all 5-HT-responsive layer $5 \mathrm{COM}$ neurons. Conversely, $\mathrm{CPn}$ neurons were universally inhibited by $5-\mathrm{HT}$. Serotonergic excitation of COM neurons was blocked by the 2A antagonist MDL 11939, while serotonergic inhibition of CPn neurons was blocked by the 1A antagonist WAY 100635, confirming a role for these two receptor subtypes in regulating pyramidal neuron activity. Selective serotonergic excitation of COM neurons was not layer-specific, as COM neurons in layer $2 / 3$ were also selectively excited by $5-\mathrm{HT}$ relative to their non-labeled pyramidal neuron neighbors. Because neocortical 2A receptors are implicated in the etiology and pathophysiology of schizophrenia, we propose that COM neurons may represent a novel cellular target for intervention in psychiatric disease.

Keywords: neocortex, cerebral cortex, serotonin, 5-HT1A receptor, 5-HT2A receptor, pyramidal neuron, corpus callosum, retrograde labeling

\section{INTRODUCTION}

Serotonin (5-hydroxytryptamine, or 5-HT) is a cortical neurotransmitter implicated in schizophrenia (Geyer and Vollenweider, 2008; Meltzer et al., 2011) and other mental health disorders (Filip and Bader, 2009). Postsynaptic serotonergic signaling in cortical pyramidal neurons relies primarily on two G-protein coupled receptors, $5-\mathrm{HT}_{1 \mathrm{~A}}(1 \mathrm{~A})$ and $5-\mathrm{HT}_{2 \mathrm{~A}}(2 \mathrm{~A})$, that have opposing influences on neuronal excitability. While most pyramidal neurons are inhibited by $5-\mathrm{HT}$ via $1 \mathrm{~A}$ receptor activation (Araneda and Andrade, 1991; Beique et al., 2004, 2007; Zhang and Arsenault, 2005; Goodfellow et al., 2009; Zhong and Yan, 2011), a minority is functionally excited via 2A receptors (Araneda and Andrade, 1991; Beique et al., 2007). Cortical 2A receptors, which are enriched in the prefrontal cortex (Pazos et al., 1985; Weber and Andrade, 2010), are of intense clinical interest because they mediate the psychotropic effects of serotonergic hallucinogens (Willins and Meltzer, 1997), are implicated in the development and etiology of schizophrenia (Benekareddy et al., 2010), and are the preferred targets for atypical antipsychotics (Gonzalez-Maeso and Sealfon, 2009). However, despite their pharmacological significance, little is known about the functional role of $2 \mathrm{~A}$ receptors in regulating the activity of cortical microcircuits.
Layer 5 pyramidal neurons (L5PNs), which provide the bulk of cortical output, have been classified into distinct subclasses based on their morphology, physiology, axonal projections, and genetic expression patterns (Arlotta et al., 2005; Molnar and Cheung, 2006; Morishima and Kawaguchi, 2006; Sugino et al., 2006; Molyneaux et al., 2007; Chen et al., 2008; Leone et al., 2008; Brown and Hestrin, 2009; Morishima et al., 2011; Oberlaender et al., 2011). Each L5PN subclass represents a unique component of the local cortical microcircuit, displaying highly selective synaptic connectivity that generates directional information flow through segregated and parallel cortical output channels (Morishima and Kawaguchi, 2006; Brown and Hestrin, 2009; Morishima et al., 2011; Otsuka and Kawaguchi, 2011). It has been hypothesized that serotonergic $2 \mathrm{~A}$-dependent excitation may be restricted to one or more L5PN subtypes (Spain, 1994; Weber and Andrade, 2010), thereby allowing 5-HT to selectively enhance cortical output to specific target structures. To test this hypothesis, we used retrograde labeling to identify subtypes of L5PNs in the mouse prefrontal cortex based on their axonal projection patterns (Morishima and Kawaguchi, 2006; Dembrow et al., 2010; Morishima et al., 2011). We report that 5-HT, via 2A receptor activation, selectively generates excitatory and biphasic responses in pyramidal neurons projecting to the contralateral cortex, while 
brainstem-projecting pyramidal neurons are inhibited by 5-HT through $1 \mathrm{~A}$ receptors. The identification of a specific pyramidal neuron subpopulation selectively excited by $2 \mathrm{~A}$ receptors enhances our conceptual framework regarding serotonergic regulation of cortical microcircuits, and suggests callosal-projection neurons may represent a novel cellular target for the treatment of schizophrenia and other psychiatric diseases.

\section{METHODS}

\section{ANIMALS}

Wild-type C57Bl/6J (3-weeks-8-months-old) and Thy-1-YFP line H (3-7-weeks-old; Jackson Laboratory; see Feng et al., 2000) mice were used in experiments according to methods approved by the Institutional Animal Care and Use Committee of Dartmouth College.

\section{RETROGRADE LABELING}

Subpopulations of pyramidal neurons were labeled based on their axonal projections using stereotaxic injections of fluorescent beads (Retrobeads from Lumafluor, Inc.; $700 \mathrm{~nL}$ of undiluted solution per injection) into the contralateral medial prefrontal cortex (mPFC) or the pons (see Figure 3) using age-appropriate coordinates (Paxinos and Franklin, 2004). Animals were anesthetized for surgery with an IP injection of 2,2,2-tribromoethanol

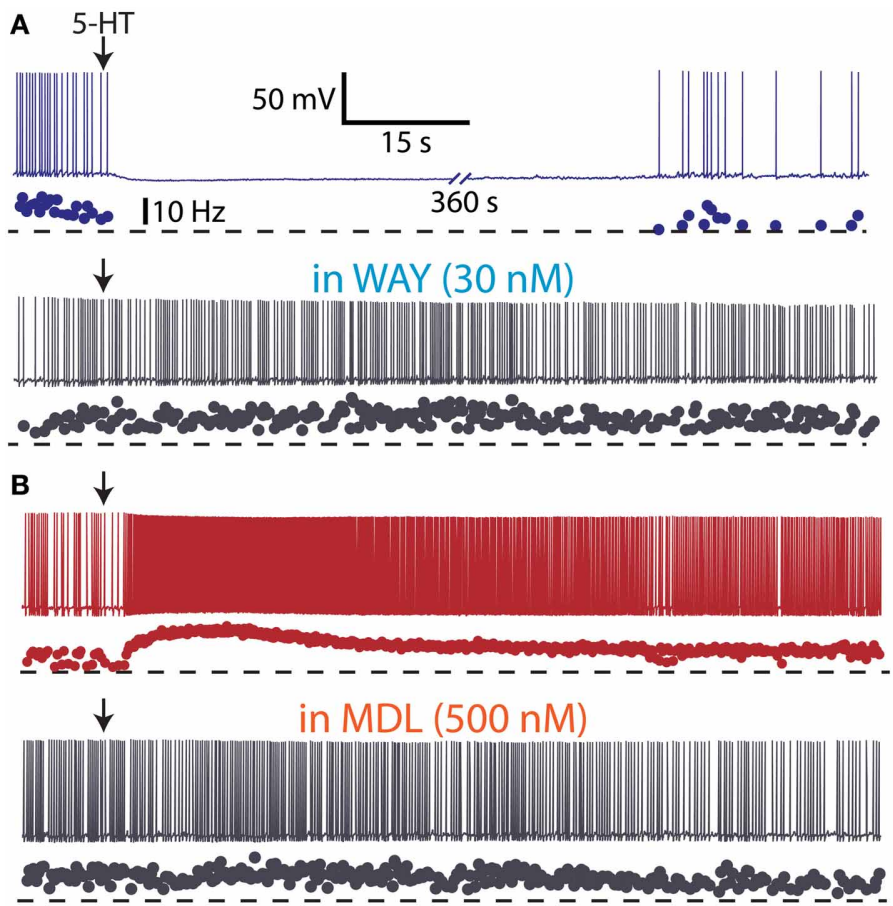

D

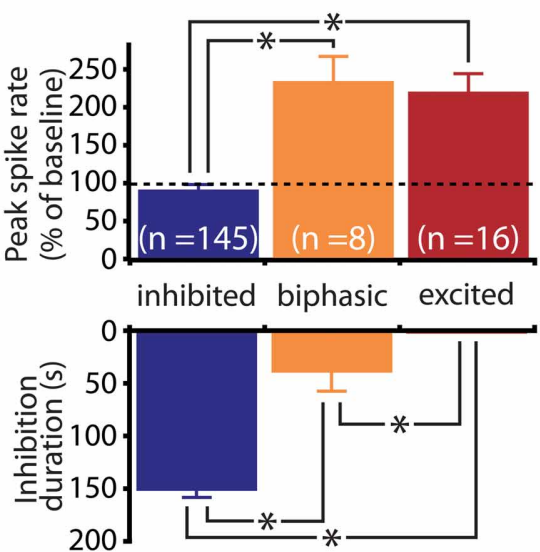

E

Adolescent (3- to 5-week-old)

L5PNs

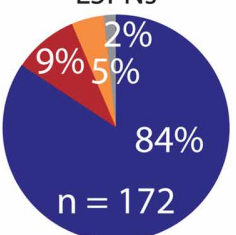

YFP + L5PNs

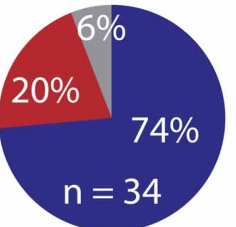

Adult

(7- to 8-month-old) L5PNs

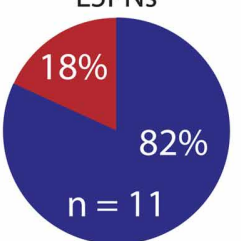

5-HT Response:

Inhibited

Excited

Biphasic

No response
FIGURE 1 | Diversity of serotonin responses in prefrontal layer 5 pyramidal neurons (L5PNs). (A-C) Responses to focal serotonin application $(100 \mu \mathrm{M}, 10 \mathrm{~s}$, beginning at arrow) in L5PNs during periods of current-driven action potential generation. Three response types were observed: inhibition, blocked by the 1A antagonist WAY 100635 (A), excitation, blocked by the 2A antagonist MDL 11939 (B), and biphasic responses consisting of short-duration inhibition followed by excitation, also sensitive to the $2 \mathrm{~A}$ antagonist (C). (D) Comparisons of the duration of inhibition (bottom) and peak changes in spike rate (top) according to serotonergic response type. (E) Proportions of L5PNs exhibiting different serotonin responses in neurons from the mPFCs of adolescent mice, fully adult mice, and adolescent Thy1-YFP mice in which a subpopulation of L5PNs are selectively labeled with yellow fluorescent protein (YFP). 
(20 mg/Kg). Surgeries lasted approximately $45 \mathrm{~min}$, after which animals were allowed to recover for $72 \mathrm{~h}$ before use in electrophysiological experiments. Locations of dye injections were confirmed in coronal sections of the mPFC or brainstem.

\section{SLICE PREPARATION}

Animals were anesthetized with isoflurane and decapitated. Brains were quickly removed into ice-cold artificial cerebral spinal fluid (ACSF) containing, in mM, $125 \mathrm{NaCl}, 25 \mathrm{NaHCO}_{3}, 3 \mathrm{KCl}$, and $1.25 \mathrm{NaH}_{2} \mathrm{PO}_{4}, 0.5 \mathrm{CaCl}_{2}, 6 \mathrm{MgCl}_{2}, 25$ glucose, and saturated with $95 \% \mathrm{O}_{2} / 5 \% \mathrm{CO}_{2}$. Coronal brain slices (200 $\mu \mathrm{m}$ thick) containing the mPFC were cut using a Leica VT 1200 slicer and transferred to a storage chamber filled with ACSF in which $\mathrm{CaCl}_{2}$ was increased to $2 \mathrm{mM}$ and $\mathrm{MgCl}_{2}$ was decreased to $1 \mathrm{mM}$. Slices were maintained at $35^{\circ} \mathrm{C}$ for approximately $1 \mathrm{~h}$, then stored at room temperature for up to $8 \mathrm{~h}$ prior to use in experiments.

\section{ELECTROPHYSIOLOGY}

Slices were transferred to a recording chamber below an Olympus BX51WI microscope and continuously perfused with oxygenated ACSF at $35^{\circ} \mathrm{C}$. Whole-cell current-clamp recordings of L5PNs were made with patch pipettes $(\sim 5 \mathrm{M} \Omega)$ filled with, in $\mathrm{mM}$, $135 \mathrm{~K}$-gluconate, $2 \mathrm{NaCl}, 2 \mathrm{MgCl}_{2}, 10 \mathrm{HEPES}, 3 \mathrm{Na}_{2} \mathrm{ATP}$, and $0.3 \mathrm{NaGTP}(\mathrm{pH} 7.2$ with $\mathrm{KOH})$. In some experiments, biocytin $(7.5 \mathrm{mg} / \mathrm{mL})$ was added to the pipette solution to allow for post-hoc visualization and morphological analysis of the recorded neuron (see below). Data were acquired with AxographX software (AxographX Company) using a BVC-700 amplifier (Dagan Corporation) and an ITC-18 digitizer (HEKA Instruments). Membrane potentials were filtered at $5 \mathrm{kHz}$, sampled at $25 \mathrm{kHz}$, and corrected for the junction potential of $12 \mathrm{mV}$. Input resistance $\left(R_{N}\right)$ was determined from the slope of the linear portion of the steady-state voltage-current relationship established with a series of somatic current injections (generally -50 to $+50 \mathrm{pA}$ ). The magnitude of "sag" rectification (indicative of HCN channels in pyramidal neuron dendrites; see Dembrow et al., 2010) was quantified using a hyperpolarizing current injection sufficient to generate a $20 \mathrm{mV}$ peak hyperpolarization relative to the resting membrane potential. Sag was defined as the relative "rebound" (percent) from peak membrane potential hyperpolarization, as measured at steady-state. Serotonergic inhibition was quantified as the duration of cessation of action potential generation following 5-HT application (see below). 5-HTinduced excitation was quantified as the peak increase in action potential rate, relative to baseline, measured over a $5 \mathrm{~s}$ period occurring around the timing of peak spike frequency following 5-HT application.

\section{DRUGS AND DRUG APPLICATION}

Patch-pipettes were filled with 5-HT $(100 \mu \mathrm{M})$ dissolved in ACSF and connected to a Toohey Spritzer (Toohey Company). Pipettes were positioned near the soma (within $50 \mu \mathrm{m}$ ) of targeted pyramidal neurons, and 5-HT was briefly applied (1 or $10 \mathrm{~s}$ ) at low-pressure ( $\sim 4$ PSI). $10 \mathrm{~s}$ applications were used in initial experiments in unlabeled tissue, while $1 \mathrm{~s}$ applications were used in tissue labeled with retrograde tracers (to reduce the prolonged duration of serotonergic inhibitory responses; compare Figure 1D with Figure 5A). Antagonists for 1A (WAY 100635; Sigma) and 2A (MDL 11939; Tocris) receptors were bath applied for $5 \mathrm{~min}$ prior to measurements of 5-HT

Table 1 | Physiology and serotonergic responsiveness of L5PN subpopulations.

\begin{tabular}{|c|c|c|c|c|}
\hline Neuron subtype & $n$ & $V_{M}(\mathrm{mV})$ & $R_{N}(\mathrm{M} \Omega)$ & $\%$ sag \\
\hline \multicolumn{5}{|c|}{ L5PNs IN UNLABELED TISSUE (3-5-WEEKS-OLD MICE) } \\
\hline Inhibited & 145 & $-77 \pm 0$ & $75 \pm 2$ & $16 \pm 0$ \\
\hline Biphasic & 8 & $-77 \pm 2$ & $77 \pm 10$ & $11 \pm 3$ \\
\hline No response & 3 & $-75 \pm 5$ & $85 \pm 4$ & $21 \pm 6$ \\
\hline Excited & 7 & $-78 \pm 2$ & $164 \pm 30^{*}$ & $11 \pm 2^{*}$ \\
\hline No response & 2 & $-80 \pm 3$ & $179 \pm 45^{*}$ & $12 \pm 4$ \\
\hline \multicolumn{5}{|c|}{ NON-LABELED L5PNs FROM OLDER MICE (29- TO 35-WEEKS-OLD) } \\
\hline Inhibited & 9 & $-76 \pm 1$ & $62 \pm 2$ & $16 \pm 1$ \\
\hline Excited & 2 & $-73 \pm 8$ & $146 \pm 36^{*}$ & $9 \pm 1$ \\
\hline \multicolumn{5}{|c|}{ CPn-LABELED L5PNs (6-9-WEEK OLD MICE) } \\
\hline Inhibited & 17 & $-76 \pm 1$ & $78 \pm 4$ & $16 \pm 1$ \\
\hline
\end{tabular}

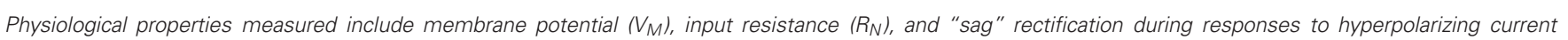

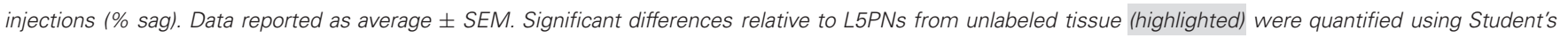

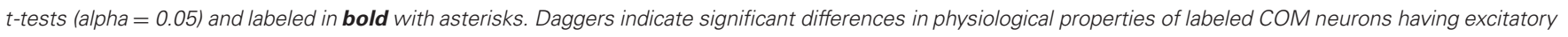
or biphasic responses to 5-HT relative to unlabeled L5PNs having the same type of responses. 
responsiveness. When used, antagonists for ionotropic glutamate (kynurenic acid, $4 \mathrm{mM}$; Sigma) and GABA (SR-95531, $10 \mu \mathrm{M}$; Sigma) receptors were bath applied for at least $5 \mathrm{~min}$ before experiments.

\section{HISTOLOGY, IMAGING, AND MORPHOLOGICAL ANALYSIS}

Slices containing biocytin-filled neurons were fixed in phosphatebuffered solution (PBS) containing 4\% paraformaldehyde and $0.2 \%$ picric acid. After $24 \mathrm{~h}$, slices were washed several times in PBS and incubated for up to $12 \mathrm{~h}$ in PBS containing $0.25 \%$ Triton X-100 and avidin conjugated to Alexa Fluor ${ }^{\circledR} 488(20 \mu \mathrm{g} / \mathrm{ml}$; Invitrogen). Slices were then dried, imbedded in FluorSave (EMD Chemicals), and imaged on a 2-photon microscope (Prairie Technologies). To compare neuron morphologies, we quantified somatic distance from the pia, maximum horizontal width of the apical tuft, the number of dendritic branch points in the tuft, and the number of primary oblique dendrites. Tracings of neurons were made using NeuronJ (freely available at http://www. imagescience.org/meijering/software/neuronj/) from z-stack projections ( $1 \mu \mathrm{m}$ sections).

\section{STATISTICAL ANALYSIS}

Data are presented as mean \pm SEM. Physiological measurements of membrane potential $\left(V_{M}\right), R_{N}$, and sag rectification in 5HT-inhibited, -excited, and -biphasic neurons were compared using One-Way ANOVAs (with Tukey-Kramer post-tests) for each parameter. One-Way ANOVAs and post-tests were also used to compare the physiology of callosal projection (5-HT-excited and -biphasic) and pontine-projecting L5PNs. Other comparisons used a 2-tailed Student's $t$-test, paired or un-paired, as appropriate. Significance was defined as $p<0.05$.

\section{RESULTS}

\section{SEROTONERGIC RESPONSES IN PREFRONTAL LAYER 5 PYRAMIDAL NEURONS}

In initial experiments, we focally applied 5-HT $(100 \mu \mathrm{M}$ for $10 \mathrm{~s})$ to L5PNs during periods of current-induced action potential generation in acute slices of unlabeled mPFC from 3-5weeks-old mice (Figure 1 and Table 1). 5-HT inhibited action potential generation in $84 \%$ (145 of 172) of unlabeled L5PNs (Figures 1A,D,E), but increased action potential frequency in another 14\% of L5PNs (24 of 172). Only a few L5PNs (3 of 172 neurons; $2 \%$ ) were not responsive to 5-HT. Serotonergic excitation occurred either alone (9\%; 15 of 172; Figures 1B,D,E), or as part of biphasic responses consisting of short-duration inhibition followed by longer-lasting excitation (5\%; 9 of 172 ; Figures 1C,D,E). In agreement with previous studies (Puig et al., 2005; Benekareddy et al., 2010), we found serotonergic inhibition and excitation were blocked by antagonists specific for $1 \mathrm{~A}$ receptors (WAY 100635, $30 \mathrm{nM} ; n=16$; Figure 1A) or $2 \mathrm{~A}$ receptors (MDL 11939, $500 \mathrm{nM} n=4$; Figures 1B,C), respectively.

In L5PNs, a well characterized developmental increase in 1A receptor expression induces a phenotypic "switch" from serotonergic excitation to serotonergic inhibition during the third postnatal week (Zhang, 2003; Beique et al., 2004). Although we used neurons from animals over 3 weeks of age, we confirmed our results did not reflect delayed maturation of L5PNs by conducting additional experiments using neurons from 7- to 8-month-old mice $(n=11)$ and from 3- to 7-week-old Thy-1 YFP line H mice $(n=34)$, in which a subpopulation of L5PNs is labeled with YFP. We found 5-HT to excite similar proportions of L5PNs (18\% and $20 \%$, respectively) in both groups (Figure 1E and Table 1).

Prefrontal L5PNs are heterogeneous in their physiological properties (Dembrow et al., 2010). To determine whether
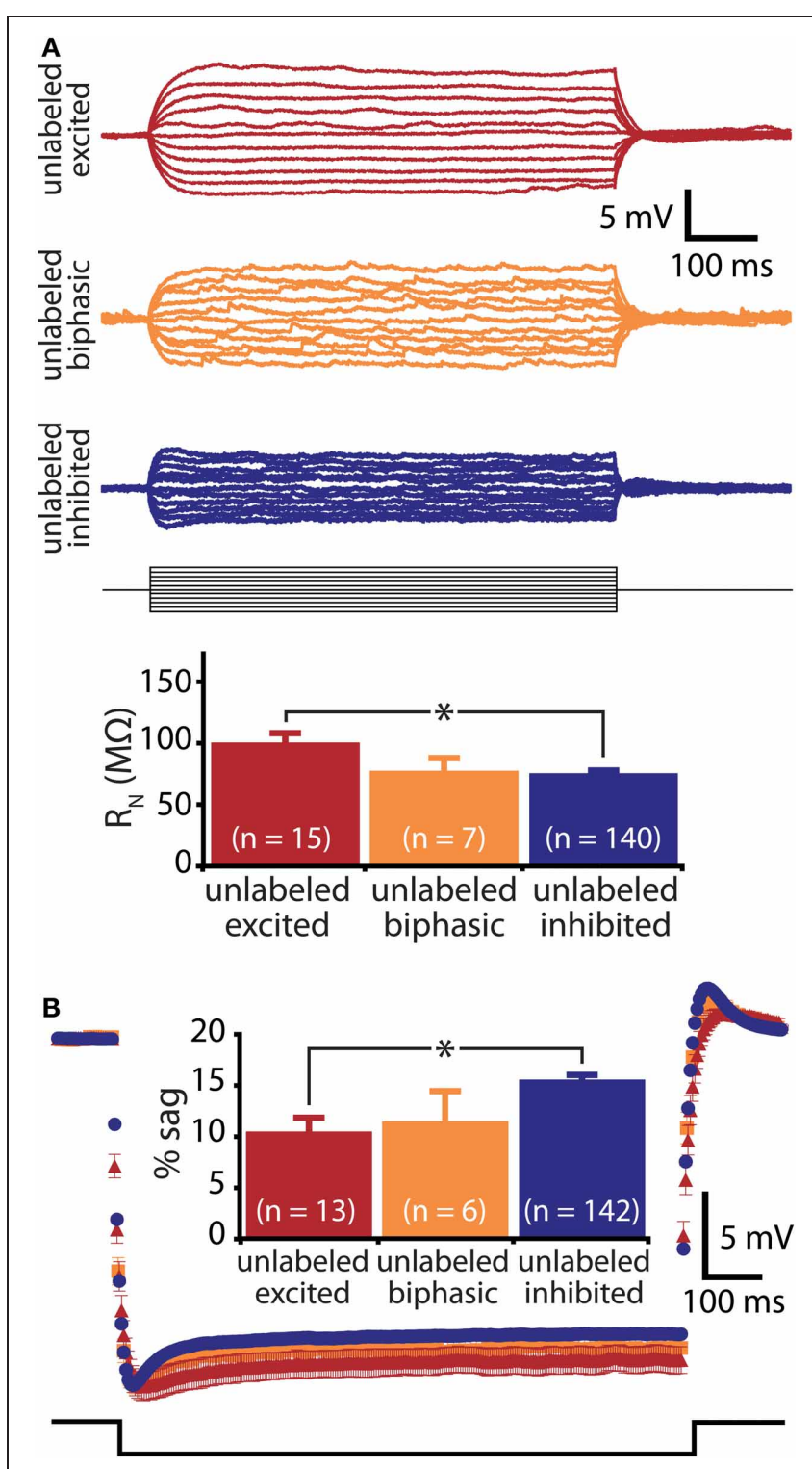

FIGURE 2 | Responsiveness to serotonin correlates with membrane physiology. (A) Top, voltage responses to somatic current injections ( -50 to $50 \mathrm{pA}$ in $5 \mathrm{pA}$ steps) in unlabeled L5PNs. Bottom, comparison of input resistance $\left(R_{N}\right)$ in neurons having different responses to serotonin. (B) Average ( \pm SEM) voltage responses to hyperpolarizing current injections sufficient to generate a peak hyperpolarization of $\sim 20 \mathrm{mV}$ in unlabeled L5PNs grouped according to their responsiveness to serotonin (blue indicates serotonergic inhibition, red indicates serotonergic excitation, and orange indicates biphasic responses). Comparison of results is inset. Asterisks indicate $p<0.05$. 
serotonergic responsiveness correlates with physiology, we compared resting $V_{M}, R_{N}$, and the amount of "sag" rectification occurring during hyperpolarizing current injections in 5-HTexcited and 5-HT-inhibited L5PNs (Figure 2 and Table 1). We found 5-HT-excited L5PNs had higher $R_{N}(100 \pm 7 \mathrm{M} \Omega)$ and less sag $(10 \pm 1 \%$ sag) than did L5PNs inhibited by $5-\mathrm{HT}$ $\left(R_{N}\right.$, and sag for inhibited L5PNs were $75 \pm 2 \mathrm{M} \Omega$ and $16 \pm$ $0 \%$, respectively, $p<0.05$ for each when compared to values from 5-HT-excited neurons). These results suggest 5-HT may selectively excite a physiologically distinct subpopulation of L5PNs.

\section{SELECTIVE SEROTONERGIC EXCITATION OF CALLOSAL/COMMISSURAL PROJECTION NEURONS}

COM projection L5PNs connecting homologous cortical areas in the two cerebral hemispheres have relatively high $R_{N}$ and modest sag rectification, physiological properties similar to those found in 5-HT-excited L5PNs (Dembrow et al., 2010). To test whether COM neurons include those excited by 5 -HT, we injected fluorescent Retrobeads unilaterally into the left mPFC and later recorded serotonergic responses in labeled COM neurons in slices of the contralateral cortex (Figure 3A). Focal 5-HT application (100 $\mu \mathrm{M}$ for $1 \mathrm{~s})$ generated excitatory $(n=15)$ or biphasic $(n=$ 9) responses in all 5-HT-responsive COM neurons (93\%; 24 of 26 tested neurons; Figures 4A,C). Purely inhibitory responses were never observed in COM neurons. Serotonergic excitation of COM neurons was blocked by MDL 11939 ( $n=5$; Figure 4D), confirming a functional role for $2 \mathrm{~A}$ receptors in regulating $\mathrm{COM}$ neuron excitability.
We next applied 5-HT to a second, non-overlapping L5PN population projecting to the pons (CPn, see Dembrow et al., 2010) (Figure 3B). In contrast to COM neurons, all CPn neurons tested $(n=17)$ were inhibited by 5 -HT (Figures 4B,C), and this inhibition was blocked by the 1A antagonist WAY 100635 $(n=4$; Figure 4D). To confirm that selective serotonergic regulation of COM and CPn L5PNs does not result from indirect modulation of excitatory drive onto L5PNs, in additional experiments we measured serotonergic responses in the presence of blockers of fast synaptic transmission (4 mM kynurenic acid, to block ionotropic glutamate receptors, and $10 \mu \mathrm{M}$ SR95531, to block $\mathrm{GABA}_{\mathrm{A}}$ receptors; see Gulledge and Stuart, 2005). With fast synaptic transmission blocked, 5-HT selectively excited all COM neurons tested $(n=12)$, generating pure excitations $(n=7)$ or biphasic excitations $(n=5)$ indistinguishable from those generated in COM neurons in the absence of synaptic blockers (Figure 5). Similarly, in the presence of synaptic blockers, 5-HT inhibited all CPn neurons tested $(n=3)$ for durations comparable to those generated in the absence of blockers (Figure 5). These data demonstrate that selective regulation of COM and CPn neuron excitability by 5 -HT does not depend on changes in fast synaptic transmission.

\section{PHYSIOLOGY AND MORPHOLOGY OF COM AND CPn NEURONS}

In the rat $\mathrm{mPFC}, \mathrm{COM}$ and $\mathrm{CPn}$ L5PNs have distinct physiological and morphological properties (Dembrow et al., 2010). To determine whether this is also the case in the mouse mPFC, we measured physiological parameters in COM and CPn neurons,

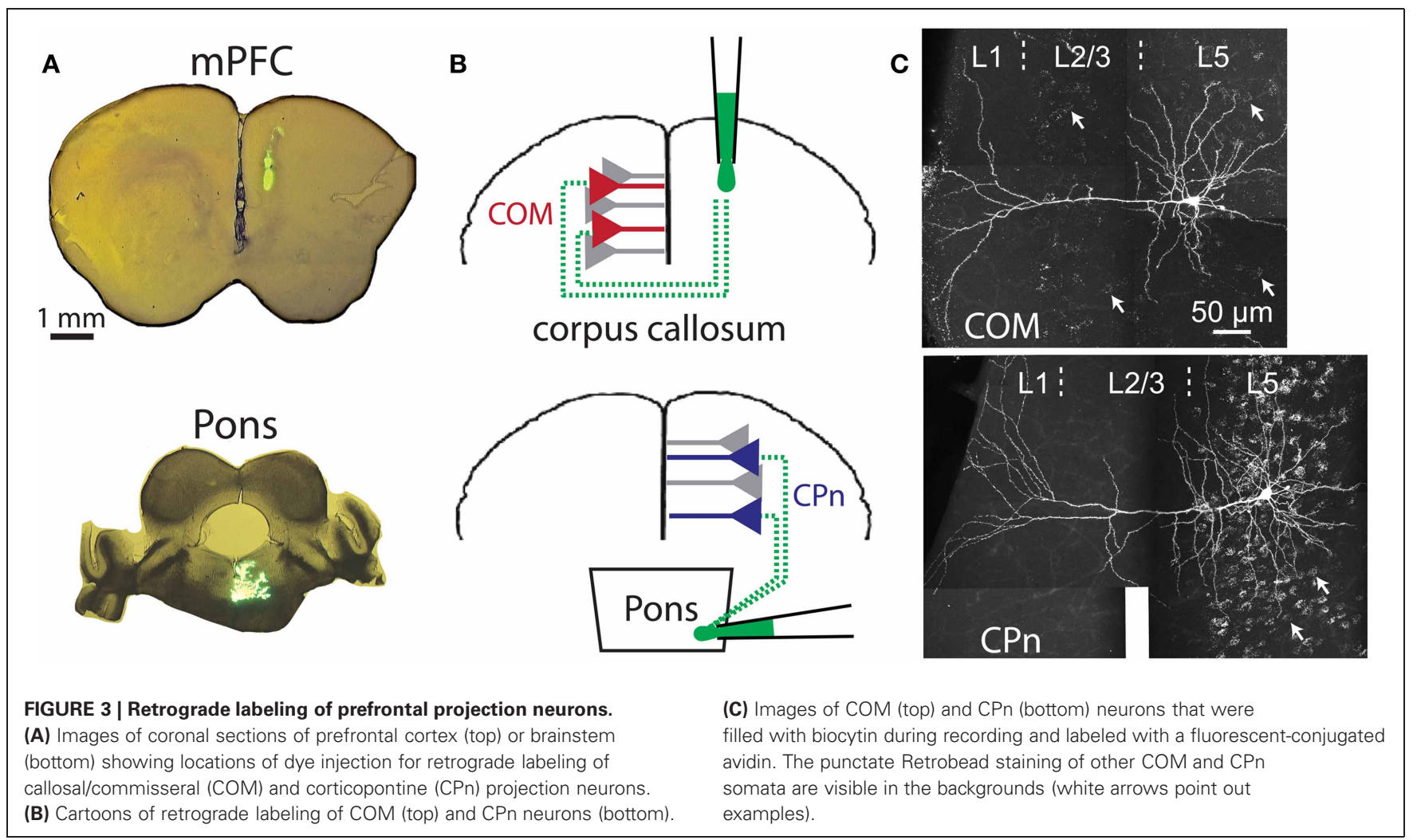




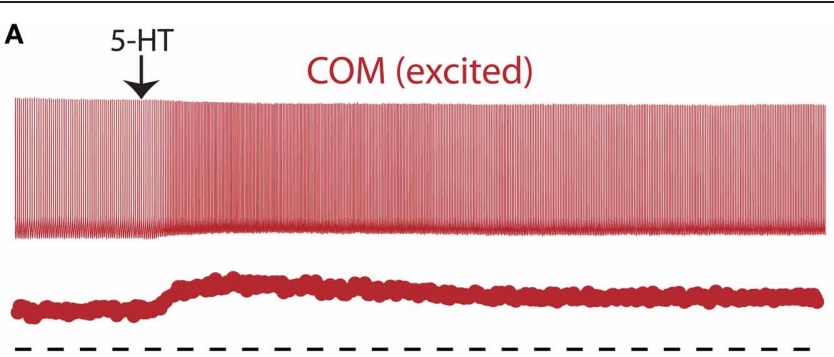

B

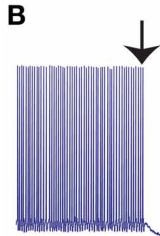

CPn (Inhibited)
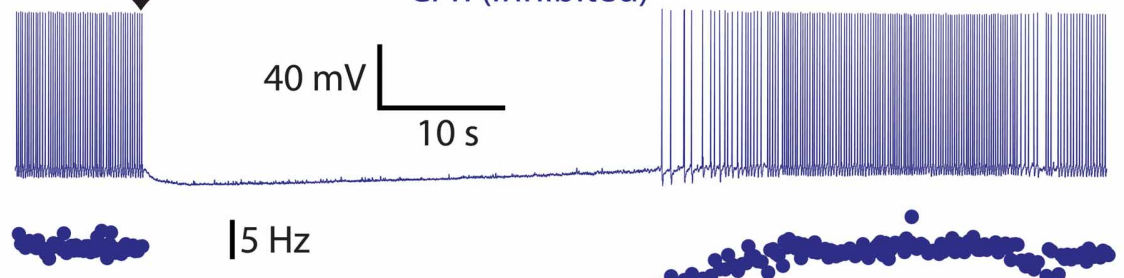

D

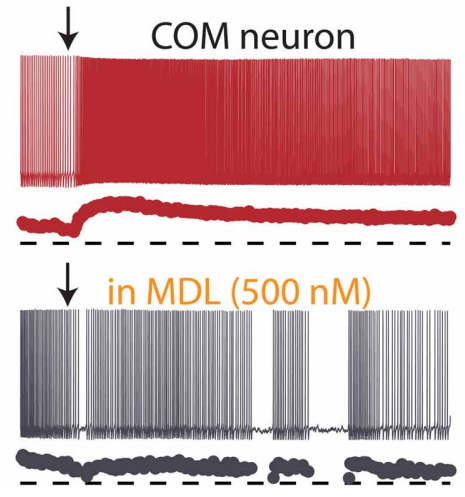

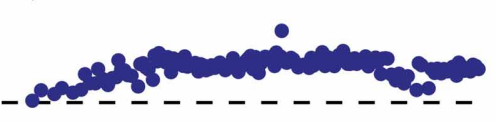

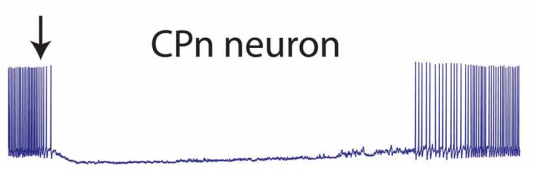

- $15 \mathrm{~Hz}$
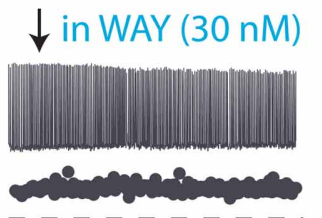

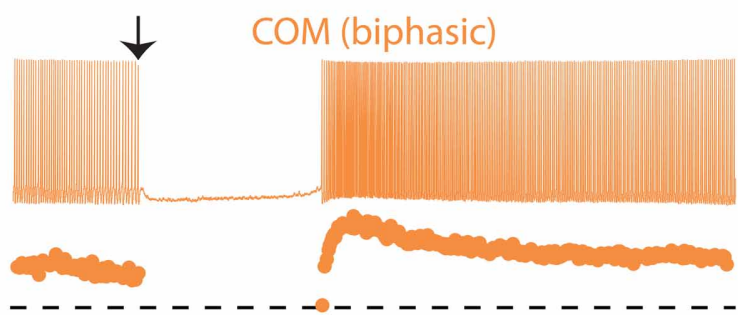

c COML5PNS
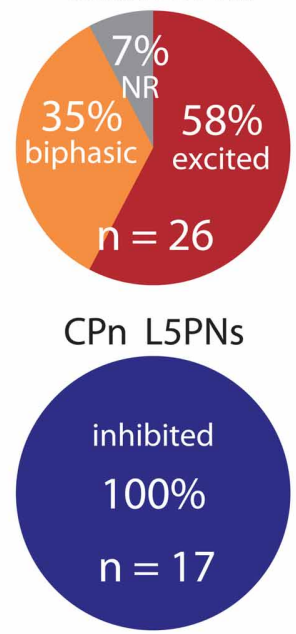

Inhibited

Excited

Biphasic

No response
FIGURE 4 | Serotonin selectively excites commissural/callosal (COM) projection neurons. (A) Excitatory (left) and biphasic (right) responses to focal serotonin application in COM neurons.

(B) Inhibitory response to serotonin in a corticopontine (CPn) neuron.

(C) Proportion of COM and CPn neurons excited (red), inhibited (blue), or having biphasic (orange) responses to 5-HT. Non-responsive neurons (NR) shown in gray. (D) Serotonergic excitation of COM neurons (left) and inhibition of CPn neurons (right) was blocked by antagonists specific for 2A (MDL 11939) or 1A (WAY 100635) receptors, respectively. and filled a subset of neurons with biocytin during recording for post-hoc analysis of morphologies (Figure 6). COM and $\mathrm{CPn}$ neurons were physiologically distinct, with COM neurons $(n=26)$ having more hyperpolarized resting membrane potentials $(-81 \pm 1 \mathrm{mV})$, higher $R_{N}(144 \pm 7 \mathrm{M} \Omega)$, and less sag rectification $(6 \pm 1 \%)$ than $\mathrm{CPn}$ neurons (mean $V_{M}, R_{N}$, and sag for $\mathrm{CPn}$ neurons were $-76 \pm 1 \mathrm{mV}, 78 \pm 4 \mathrm{M} \Omega$, and $16 \pm$ $1 \%$, respectively; $p<0.05$ for each; Figures 6 A,B, and Table $\mathbf{1}$ ). $\mathrm{COM}$ neurons were also morphologically distinct from $\mathrm{CPn}$ neurons, having more superficial somata (somatic depths were $332 \pm$ $18 \mu \mathrm{m}$ vs. $405 \pm 14 \mu \mathrm{m}$ ), more horizontally compact apical tufts (maximal tuft widths were $211 \pm 30 \mu \mathrm{m}$ vs. $302 \pm 34 \mu \mathrm{m}$ ), and fewer basal ( $6.7 \pm 0.7$ vs. $9.2 \pm 1.0)$, oblique ( $4.6 \pm 0.7$ vs. $13.3 \pm$ $1.2)$, and tuft ( $4.0 \pm 0.7$ vs. $7.2 \pm 0.7)$ dendritic branches, than CPn neurons ( $n=10$ for each group; $p<0.05$ for each group, paired Student's $t$-tests; Figures $6 \mathrm{C}-\mathbf{H}$ ). Together, these data demonstrate selective and opposing serotonergic regulation of distinct L5PN subtypes in the mouse prefrontal cortex.

\section{SELECTIVE SEROTONERGIC EXCITATION OF COM NEURONS IN LAYER 2/3}

In the mPFC, COM neuron somata are found in both layer 5 and layer 2/3 (Morishima and Kawaguchi, 2006). We focally applied 5-HT to COM-labeled and neighboring non-labeled layer $2 / 3$ pyramidal neurons (L2/3PNs) to test whether selective serotonergic excitation of COM neurons is conserved across cortical lamina (Figure 7). Indeed, out of 21 COM-labeled L2/3PNs, 18 showed excitatory or biphasic responses. No COM L2/3PNs had purely inhibitory responses to 5-HT (3 COM L2/3PNs were not responsive to 5-HT). On the other hand, two-thirds of non-labeled L2/3PNs ( $n=12$ of 18 ) were inhibited by 5 -HT, while another third $(n=6)$ exhibited excitatory responses. Physiological properties of COM and unlabeled L2/3PNs were, for the most part, similar and independent of their serotonergic responsiveness. The exception was the finding of a higher input resistance in COM L2/3PNs, relative to their unlabeled neighbors (Table 2). Together, these data demonstrate that selective excitation of COM 


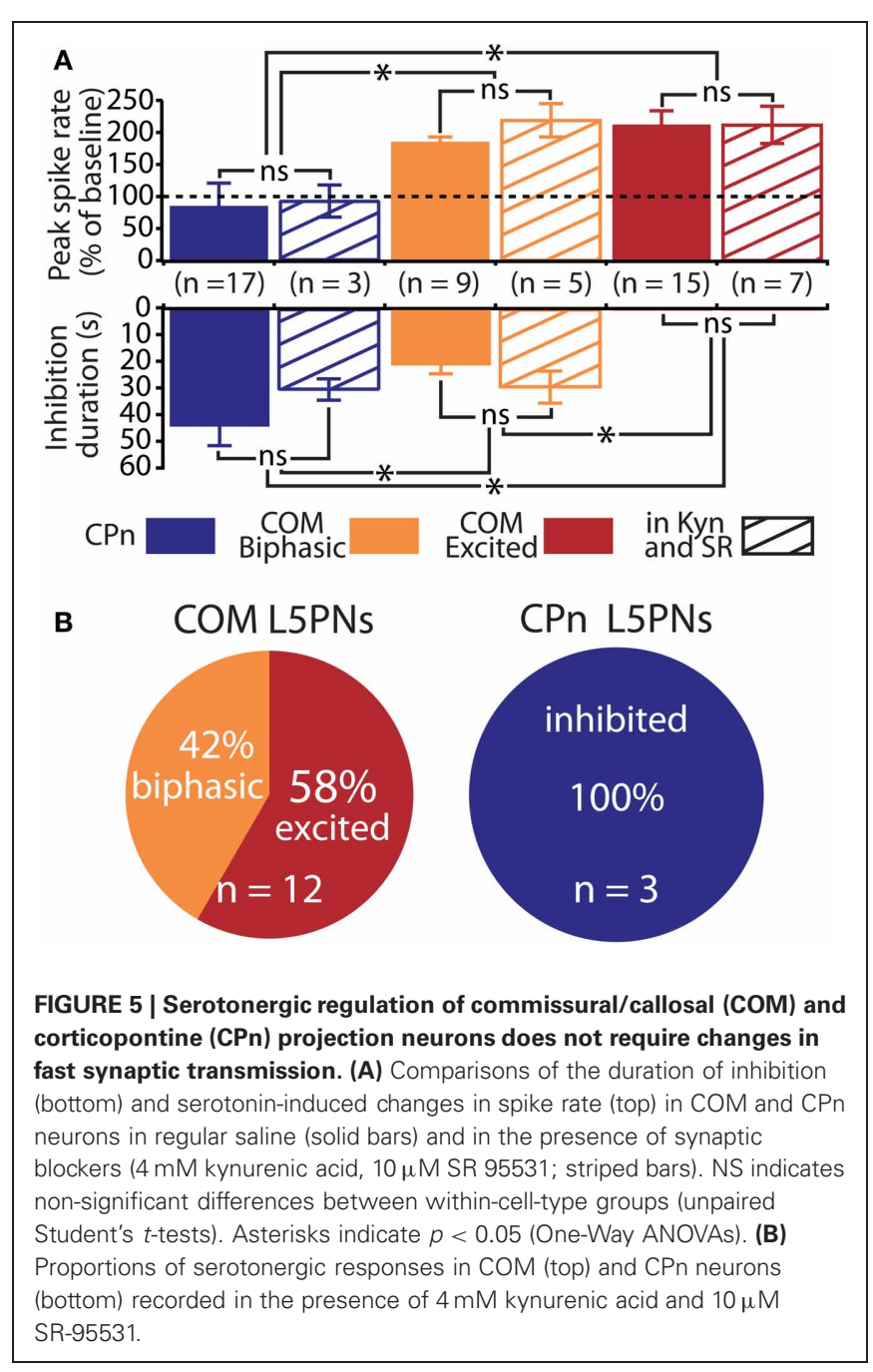

neurons is not restricted to layer 5 , but appears instead to be a common feature of prefrontal COM neurons.

\section{DISCUSSION}

We found that 5-HT selectively increases the excitability of COM neurons by activation of $2 \mathrm{~A}$ receptors, while inhibiting output from the vast majority of cortical pyramidal neurons, including all CPn neurons, via $1 \mathrm{~A}$ receptor activation. Because $2 \mathrm{~A}$ receptors in the prefrontal cortex are implicated in the pathophysiology of schizophrenia (Willins and Meltzer, 1997; Gonzalez-Maeso and Sealfon, 2009; Benekareddy et al., 2010), our data suggest excessive activation of COM neurons, which provide the bulk of long-range intra- and inter-hemispheric cortico-cortical projections (Otsuka and Kawaguchi, 2011), may play a central role in psychosis. We, therefore, propose that COM neurons represent a novel cellular, rather than molecular, target for the treatment of psychiatric diseases involving dysregulation of $2 \mathrm{~A}$ receptor signaling.

\section{SELECTIVE EXCITATION OF COM NEURONS}

We found three distinct responses to 5-HT in L5PNs from unlabeled tissue: 1A-mediated inhibition, 2A-mediated excitation, and biphasic responses resulting from coactivation of $1 \mathrm{~A}$ and $2 \mathrm{~A}$ receptors. 5-HT-excited L5Ns had physiological properties characteristic of COM neurons (Dembrow et al., 2010), and experiments targeting labeled COM neurons confirmed that this population is selectively excited by 5 -HT via $2 \mathrm{~A}$ receptors. On the other hand, 5-HT inhibited all labeled CPn neurons via 1A receptor activation. These data are significant in demonstrating, for the first time, selective serotonergic activation of a specific cortical output channel. 2A receptor-dependent serotonergic excitation of COM neurons may also explain the parallel rostral-to-caudal gradients found for cortical 2A receptor expression (Pazos et al., 1985; Weber and Andrade, 2010) and COM neuron density (Chao et al., 2009).

Two observations suggest that 5-HT may excite additional, non-COM L5PN populations. First, differences in membrane physiology were more exaggerated when comparing 5-HTinhibited CPn neurons with excited and biphasic COM neurons than when comparing unlabeled L5PNs grouped according to their serotonergic response. For instance, $\mathrm{CPn}$ neurons were significantly more hyperpolarized than were COM neurons, but $V_{M}$ was not well correlated with serotonin responsiveness in unlabeled L5PNs (Table 1, compare also Figure 2B with Figure 6B). Second, biphasic and excited COM neurons exhibited physiological properties distinct from the populations of excited and biphasic neurons found in unlabeled tissue. For instance, COM neurons had higher $R_{N}$ values than did unlabeled L5PNs excited by 5 -HT (Table $\mathbf{1}$ ).

It is possible that some of the physiological differences observed in labeled and unlabeled L5PNs reflect unintentional selection bias when visually choosing unlabeled neurons for whole-cell recording. For instance, the tendency to target larger, more prominent somata could contribute to the lower input resistances found in unlabeled 5-HT-excited neurons. Similarly, targeting of larger neurons in unlabeled tissue might bias selection toward L5PNs projecting toward the brainstem (Morishima and Kawaguchi, 2006; Dembrow et al., 2010), which may explain why only $15 \%$ of unlabeled L5PNs showed 2A-dependent excitation even while COM neurons, which were overwhelmingly excited by 5 -HT, make up closer to $25 \%$ of all L5PNs (Hattox and Nelson, 2007). Alternatively, differences in the physiology of COM neurons and unlabeled 5-HT-excited L5PNs are consistent with the hypothesis that additional L5PN subpopulations are excited via $2 \mathrm{~A}$ receptor activation. Additional studies will be needed to test serotonergic responsiveness of other L5PN projection subtypes, such as those projecting to the thalamus, the ventral tegmentum, and dorsal raphe. It will also be necessary to test whether selective serotonergic activation of COM neurons is conserved across species. For instance, Beique et al. (2007) found that "approximately one-third" of deep layer pyramidal neurons in the rat $\mathrm{mPFC}$ are excited by $2 \mathrm{~A}$ receptor activation. Our results suggest that the 5-HT-excited subpopulation of pyramidal neurons in the rat cortex may include COM neurons. Such a finding would suggest that 2A-dependent excitation of COM neurons may be a conserved feature of the mammalian prefrontal cortex.

\section{ROLE OF SEROTONIN IN CORTICAL FUNCTION AND PATHOLOGY}

The quest to identify a role of 5-HT in regulating cortical activity has been marked by the apparent paradox that pyramidal 


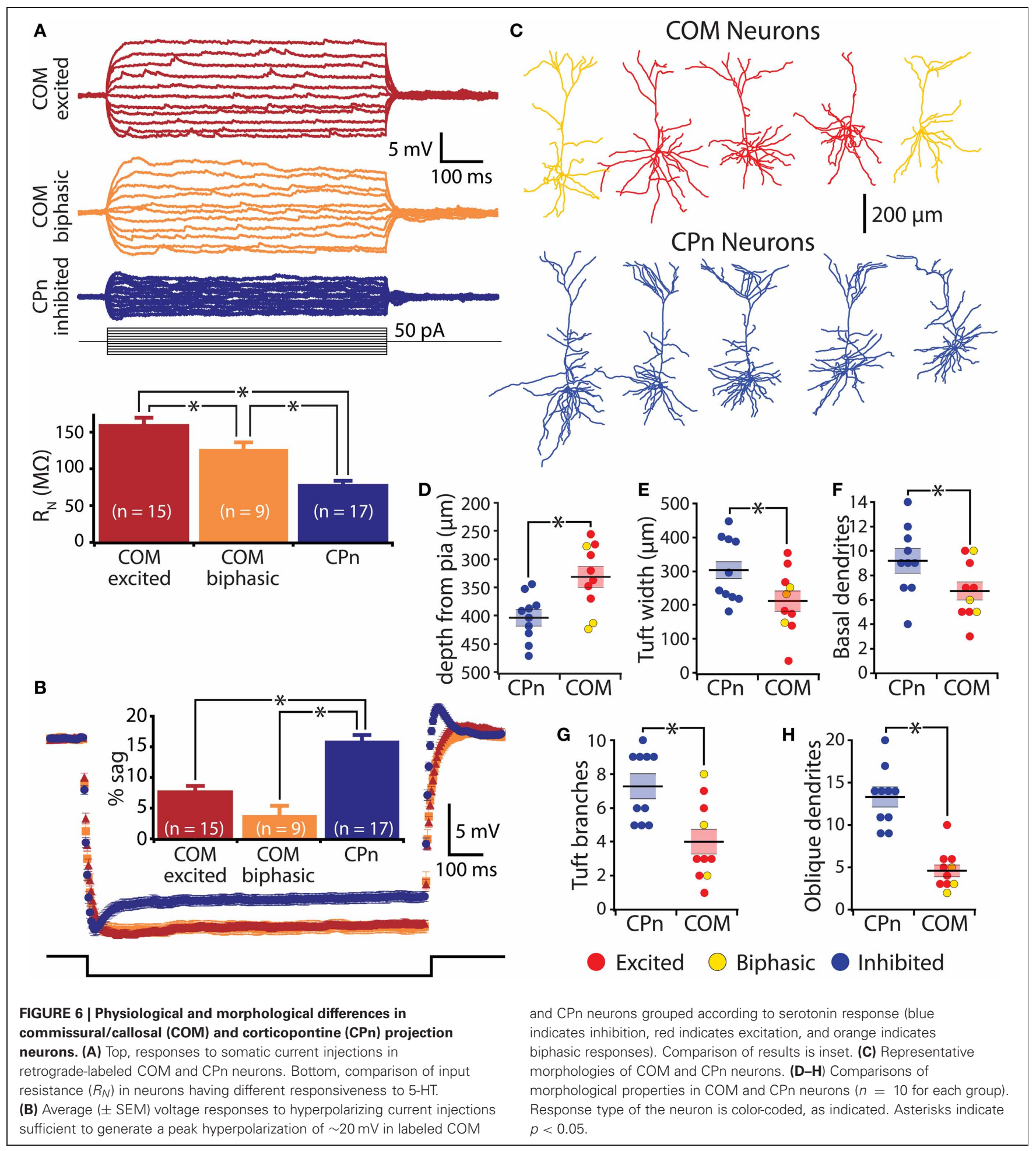

neurons express both inhibitory (1A) and excitatory (2A) receptors (Amargos-Bosch et al., 2004; Santana et al., 2004; Puig et al., 2010), yet the majority of adult pyramidal neurons are functionally inhibited by 5-HT (Araneda and Andrade, 1991; Beique et al., 2004; Zhang and Arsenault, 2005; Beique et al., 2007; Goodfellow et al., 2009; Zhong and Yan, 2011). 2A receptors expressed by non-COM neurons may have important roles independent of direct modulation of intrinsic membrane excitability. For instance, $2 \mathrm{~A}$ receptors may regulate synaptic transmission and plasticity by influencing AMPA and NMDA receptor function (Yuen et al., 2008; Zhong et al., 2008a,b). Our data demonstrate $2 \mathrm{~A}$ receptors selectively enhance action potential generation in 


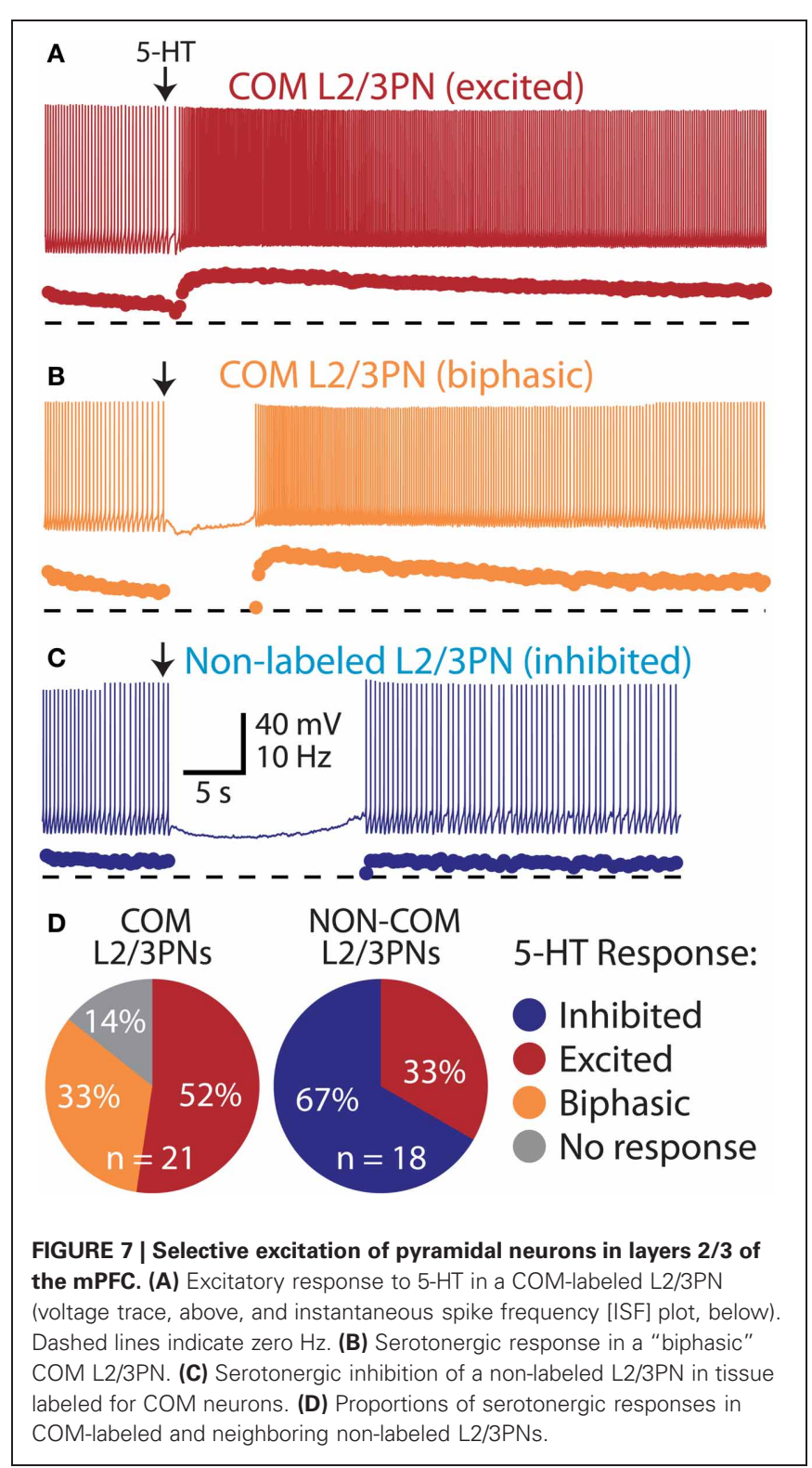

COM neurons independent of synaptic input, but do not preclude the possibility that $2 \mathrm{~A}$ receptors may also have effects on synaptic transmission in these neurons. Our finding opposing actions of 5-HT in COM and CPn neurons add to a growing body of evidence pointing to highly selective serotonergic modulation of cellular components within cortical microcircuits (Zhou and Hablitz, 1999; Foehring et al., 2002; Xiang and Prince, 2003; Amargos-Bosch et al., 2004; Puig et al., 2004; Kruglikov and Rudy, 2008; Lee et al., 2010).

How does selective activation of COM neurons facilitate information processing in the prefrontal cortex? COM neurons are synaptically coupled to each other, and provide unidirectional excitatory input to CPn neurons (Morishima and Kawaguchi, 2006), suggesting that serotonergic activation of COM neurons may increase glutamate release onto both COM and CPn neurons, while direct 1A-dependent inhibition of CPn output would have
Table 2 | Physiology and serotonergic responsiveness of L2/3PNs.

\begin{tabular}{lllll}
\hline Neuron subtype & $\boldsymbol{n}$ & $\boldsymbol{V}_{\boldsymbol{M}}(\mathbf{m V})$ & $\boldsymbol{R}_{\boldsymbol{N}}(\mathbf{M} \boldsymbol{\Omega})$ & $\% \mathbf{s a g}$ \\
\hline NON-LABELED L2/3PNs & $($ IN COM-LABELED TISSUE) & \\
Inhibited & 12 & $-79 \pm 2$ & $144 \pm 14$ & $5 \pm 1$ \\
Excited & 6 & $-79 \pm 1$ & $147 \pm 16$ & $5 \pm 1$ \\
Total L2/3 Non-COM & 18 & $-80 \pm 2$ & $142 \pm 10$ & $5 \pm 1$ \\
COM L2/3PNs & & & & \\
Excited & 11 & $-79 \pm 1$ & $171 \pm 10$ & $5 \pm 1$ \\
Biphasic & 7 & $-79 \pm 2$ & $180 \pm 14$ & $5 \pm 1$ \\
No response & 3 & $-78 \pm 2$ & $218 \pm 43$ & $7 \pm 3$ \\
Total L2/3 COM & 21 & $-79 \pm 1$ & $\mathbf{1 8 1} \pm \mathbf{9}^{*}$ & $5 \pm 1$ \\
\hline
\end{tabular}

Physiological properties measured include membrane potential $\left(V_{M}\right)$, input resistance $\left(R_{N}\right)$, and "sag" rectification during responses to hyperpolarizing current injections. Data reported as mean \pm SEM. Summary data for all unlabeled or COM-labeled neurons (independent of 5-HT responses) are highlighted. COMlabeled and unlabeled L2/3PNs were similar in most regards, with the exception of $R_{N}$, which was significantly higher in COM-labeled neurons (bold with asterisk; Student's t-test, $p<0.05)$.

little impact on ongoing COM neuron activity. If 5-HT-excited neurons are reciprocally connected (Morishima et al., 2011), 5HT could promote reverberatory excitation in small networks of interconnected COM neurons (see also Williams et al., 2002), whose collateral connections to other COM and CPn neurons might underly 2A-dependent increases in spontaneous excitatory synaptic transmission (Aghajanian and Marek, 1997; Zhou and Hablitz, 1999; Lambe et al., 2000; Beique et al., 2007). Concurrent serotonergic inhibition of CPn and other L5PN subtypes would further enhance the overall signal-to-noise of cortical output to the brainstem.

Serotonin also regulates the activity of cortical GABAergic interneurons (Zhou and Hablitz, 1999; Murakoshi et al., 2001; Foehring et al., 2002; Xiang and Prince, 2003; Weber and Andrade, 2010) and suppresses transmitter release from axon terminals (Tanaka and North, 1993; Zhou and Hablitz, 1999; Torres-Escalante et al., 2004; Kruglikov and Rudy, 2008; TrocaMarin and Geijo-Barrientos, 2010), both of which might selectively gate information flow in cortical microcircuits. For instance, ionotropic $5-\mathrm{HT}_{3 \mathrm{~A}}$ receptors are expressed by most, if not all, layer 1 interneurons (Foehring et al., 2002; Weber and Andrade, 2010), where 5- $\mathrm{HT}_{3 \mathrm{~A}}$-mediated excitation would be expected to enhance feed-forward inhibition of pyramidal neuron apical dendrites. Similarly, much as selective serotonergic regulation of pyramidal neuron excitability accounts for the heterogeneity of 5-HT responses reported in previous studies, selective control of transmitter release at synapses according to their pre- and postsynaptic identity may explain the diversity of effects of 5-HT on synaptic transmission (e.g., as in Troca-Marin and Geijo-Barrientos, 2010). Dedicated studies will be necessary to characterize selective serotonergic control of these other components of cortical microcircuits.

Finally, the precision with which 5-HT selectively regulates cortical output channels may explain why disruption of 
serotonergic signaling contributes to a wide variety of mental health disorders. In particular, excessive $2 \mathrm{~A}$ receptor activation is implicated in the etiology of many psychiatric conditions, including depression, anxiety, and schizophrenia, while 2A antagonists are efficacious in treating these disorders (Naughton et al., 2000). The selective 2A-dependent excitation of COM neurons described here suggests these neurons may represent a novel cellular target for intervention in psychiatric disease.

\section{REFERENCES}

Aghajanian, G. K., and Marek, G. J. (1997). Serotonin induces excitatory postsynaptic potentials in apical dendrites of neocortical pyramidal cells. Neuropharmacology 36, 589-599.

Amargos-Bosch, M., Bortolozzi, A., Puig, M. V., Serrats, J., Adell, A., Celada, P., Toth, M., Mengod, G., and Artigas, F. (2004). Coexpression and in vivo interaction of serotonin1A and serotonin $2 \mathrm{~A}$ receptors in pyramidal neurons of prefrontal cortex. Cereb. Cortex 14, 281-299.

Araneda, R., and Andrade, R. (1991). 5-Hydroxytryptamine2 and 5hydroxytryptamine $1 \mathrm{~A}$ receptors mediate opposing responses on membrane excitability in rat association cortex. Neuroscience 40, 399-412.

Arlotta, P., Molyneaux, B. J., Chen, J., Inoue, J., Kominami, R., and Macklis, J. D. (2005). Neuronal subtype-specific genes that control corticospinal motor neuron development in vivo. Neuron 45, 207-221.

Beique, J. C., Campbell, B., Perring, P., Hamblin, M. W., Walker, P., Mladenovic, L., and Andrade, R. (2004). Serotonergic regulation of membrane potential in developing rat prefrontal cortex: coordinated expression of 5-hydroxytryptamine (5-HT)1A, 5-HT2A, and 5-HT7 receptors. J. Neurosci. 24, 4807-4817.

Beique, J. C., Imad, M., Mladenovic, L., Gingrich, J. A., and Andrade, R. (2007). Mechanism of the 5-hydroxytryptamine $2 \mathrm{~A}$ receptormediated facilitation of synaptic activity in prefrontal cortex. Proc. Natl. Acad. Sci. U.S.A. 104, 9870-9875.

Benekareddy, M., Goodfellow, N. M., Lambe, E. K., and Vaidya, V. A. (2010). Enhanced function of prefrontal serotonin 5-HT(2) receptors in a rat model of psychiatric vulnerability. J. Neurosci. 30, 12138-12150.

Brown, S. P., and Hestrin, S. (2009). Intracortical circuits of pyramidal neurons reflect their long-range axonal targets. Nature 457, 1133-1136.

Chao, Y. P., Cho, K. H., Yeh, C. H., Chou, K. H., Chen, J. H., and Lin, C. P. (2009). Probabilistic topography of human corpus callosum using cytoarchitectural parcellation and high angular resolution diffusion imaging tractography. Hum. Brain Mapp. 30, 3172-3187.

Chen, B., Wang, S. S., Hattox, A. M. Rayburn, H., Nelson, S. B., and Mcconnell, S. K. (2008). The Fezf2Ctip2 genetic pathway regulates the fate choice of subcortical projection neurons in the developing cerebral cortex. Proc. Natl. Acad. Sci. U.S.A 105, 11382-11387.

Dembrow, N. C., Chitwood, R. A., and Johnston, D. (2010). Projectionspecific neuromodulation of medial prefrontal cortex neurons. J. Neurosci. 30, 16922-16937.

Feng, G., Mellor, R. H., Bernstein, M., Keller-Peck, C., Nguyen, Q. T., Wallace, M., Nerbonne, J. M., Lichtman, J. W., and Sanes, J. R. (2000). Imaging neuronal subsets in transgenic mice expressing multiple spectral variants of GFP. Neuron 28, $41-51$.

Filip, M., and Bader, M. (2009). Overview on 5-HT receptors and their role in physiology and pathology of the central nervous system. Pharmacol. Rep. 61, 761-777.

Foehring, R. C., van Brederode, J. F., Kinney, G. A., and Spain, W. J. (2002). Serotonergic modulation of supragranular neurons in rat sensorimotor cortex. J. Neurosci. 22, 8238-8250.

Geyer, M. A., and Vollenweider, F. X. (2008). Serotonin research: contributions to understanding psychoses. Trends Pharmacol. Sci. 29, 445-453.

Gonzalez-Maeso, J., and Sealfon, S. C. (2009). Psychedelics and schizophrenia. Trends Neurosci. 32, 225-232.

Goodfellow, N. M., Benekareddy, M., Vaidya, V. A., and Lambe, E. K. (2009). Layer II/III of the prefrontal cortex: inhibition by the serotonin 5-HT1A receptor in development and stress. J. Neurosci. 29, 10094-10103.

\section{ACKNOWLEDGMENTS}

This work was supported by PHS grant R01 MH83806 (Allan T. Gulledge) and a NARSAD Young Investigator Award from the Brain and Behavior Research Foundation (Allan T. Gulledge). The authors thank Allie Rudkin, Pamela Yeh, and Alex Bender for technical assistance, Ken Orndorff for assistance with microscopy, and Sameera Dasari, Byran Luikart, and Vicky Puig for helpful comments on the manuscript.

Gulledge, A. T., and Stuart, G. J. (2005) Cholinergic inhibition of neocortical pyramidal neurons. J. Neurosci. $25,10308-10320$

Hattox, A. M., and Nelson, S. B. (2007) Layer $\mathrm{V}$ neurons in mouse cortex projecting to different targets have distinct physiological properties. J. Neurophysiol. 98, 3330-3340.

Kruglikov, I., and Rudy, B. (2008) Perisomatic GABA release and thalamocortical integration onto neocortical excitatory cells are regulated by neuromodulators. Neuron 58, 911-924.

Lambe, E. K., Goldman-Rakic, P. S. and Aghajanian, G. K. (2000) Serotonin induces EPSCs preferentially in layer $\mathrm{V}$ pyramidal neurons of the frontal cortex in the rat. Cereb. Cortex 10, 974-980.

Lee, S., Hjerling-Leffler, J., Zagha E., Fishell, G., and Rudy, B. (2010). The largest group of superficial neocortical GABAergic interneurons expresses ionotropic serotonin receptors. J. Neurosci. 30, 16796-16808

Leone, D. P., Srinivasan, K., Chen, B. Alcamo, E., and Mcconnell, S. K. (2008). The determination of projection neuron identity in the developing cerebral cortex. Curr. Opin. Neurobiol. 18, 28-35.

Meltzer, H. Y., Horiguchi, M., and Massey, B. W. (2011). The role of serotonin in the NMDA receptor antagonist models of psychosis and cognitive impairment. Psychopharmacology (Berl.) 213, 289-305

Molnar, Z., and Cheung, A. F. (2006) Towards the classification of subpopulations of layer $\mathrm{V}$ pyramidal projection neurons. Neurosci. Res. 55, 105-115.

Molyneaux, B. J., Arlotta, P., Menezes, J. R., and Macklis, J. D. (2007) Neuronal subtype specification in the cerebral cortex. Nat. Rev. Neurosci. 8, 427-437.

Morishima, M., and Kawaguchi, Y (2006). Recurrent connection patterns of corticostriatal pyramidal cells in frontal cortex. J. Neurosci. 26, 4394-4405.

Morishima, M., Morita, K., Kubota, Y., and Kawaguchi, Y. (2011). Highly differentiated projection-specific cortical subnetworks. J. Neurosci. 31, 10380-10391.

Murakoshi, T., Song, S. Y., Konishi, S., and Tanabe, T. (2001). Multiple G-protein-coupled receptors mediate presynaptic inhibition at single excitatory synapses in the rat visual cortex. Neurosci. Lett. 309, 117-120.

Naughton, M., Mulrooney, J. B., and Leonard, B. E. (2000). A review of the role of serotonin receptors in psychiatric disorders. Hum. Psychopharmacol. 15, 397-415.

Oberlaender, M., Boudewijns, Z. S., Kleele, T., Mansvelder, H. D., Sakmann, B., and De Kock, C. P. (2011). Three-dimensional axon morphologies of individual layer 5 neurons indicate cell type-specific intracortical pathways for whisker motion and touch. Proc. Natl. Acad. Sci. U.S.A. 108, 4188-4193.

Otsuka, T., and Kawaguchi, Y. (2011). Cell diversity and connection specificity between callosal projection neurons in the frontal cortex. J. Neurosci. 31, 3862-3870.

Paxinos, G., and Franklin, K. B. J. (2004). The Mouse Brain in Stereotaxic Coordinates. San Diego, CA: Elsevier Academic Press.

Pazos, A., Cortes, R., and Palacios, J. M. (1985). Quantitative autoradiographic mapping of serotonin receptors in the rat brain. II. Serotonin-2 receptors. Brain Res. 346, 231-249.

Puig, M. V., Artigas, F., and Celada, P. (2005). Modulation of the activity of pyramidal neurons in rat prefrontal cortex by raphe stimulation in vivo: involvement of serotonin and GABA. Cereb. Cortex 15, 1-14.

Puig, M. V., Santana, N., Celada, P., Mengod, G., and Artigas, F (2004). In vivo excitation of GABA interneurons in the medial prefrontal cortex through 5-HT3 receptors. Cereb. Cortex 14, 1365-1375.

Puig, M. V., Watakabe, A., Ushimaru, M., Yamamori, T., and Kawaguchi, Y. (2010). Serotonin modulates fast-spiking interneuron and synchronous activity in the rat prefrontal cortex through 5-HT1A and 5-HT2A receptors. J. Neurosci. $30,2211-2222$. 
Santana, N., Bortolozzi, A., Serrats, J., Mengod, G., and Artigas, F. (2004). Expression of serotonin $1 \mathrm{~A}$ and serotonin2A receptors in pyramidal and GABAergic neurons of the rat prefrontal cortex. Cereb. Cortex 14, 1100-1109.

Spain, W. J. (1994). Serotonin has different effects on two classes of Betz cells from the cat. J. Neurophysiol. 72, 1925-1937.

Sugino, K., Hempel, C. M., Miller, M. N., Hattox, A. M., Shapiro, P., Wu, C., Huang, Z. J., and Nelson, S. B. (2006). Molecular taxonomy of major neuronal classes in the adult mouse forebrain. Nat. Neurosci. 9, 99-107.

Tanaka, E., and North, R. A. (1993). Actions of 5-hydroxytryptamine on neurons of the rat cingulate cortex. J. Neurophysiol. 69, 1749-1757.

Torres-Escalante, J. L., Barral, J. A., Ibarra-Villa, M. D., Perez-Burgos, A., Gongora-Alfaro, J. L., and Pineda, J. C. (2004). 5-HT1A, 5-HT2, and GABAB receptors interact to modulate neurotransmitter release probability in layer $2 / 3$ somatosensory rat cortex as evaluated by the paired pulse protocol. J. Neurosci. Res. 78, 268-278.

Troca-Marin, J. A., and GeijoBarrientos, E. (2010). Inhibition by 5 -HT of the synaptic responses evoked by callosal fibers on cortical neurons in the mouse. Pflugers Arch. 460, 1073-1085.

Weber, E. T., and Andrade, R. (2010). Htr2a Gene and 5-HT(2A) Receptor Expression in the Cerebral Cortex Studied Using Genetically Modified Mice. Front. Neurosci. 4:36. doi: 10.3389/fnins.2010.00036

Williams, G. V., Rao, S. G., and Goldman-Rakic, P. S. (2002). The physiological role of 5-HT2A receptors in working memory. J. Neurosci. 22, 2843-2854.

Willins, D. L., and Meltzer, H. Y. (1997). Direct injection of 5-HT2A receptor agonists into the medial prefrontal cortex produces a head-twitch response in rats. J. Pharmacol. Exp. Ther. 282, 699-706.

Xiang, Z., and Prince, D. A. (2003). Heterogeneous actions of serotonin on interneurons in rat visual cortex. J. Neurophysiol. 89, 1278-1287.

Yuen, E. Y., Jiang, Q., Chen, P., Feng, J., and Yan, Z. (2008). Activation of $5-\mathrm{HT} 2 \mathrm{~A} / \mathrm{C}$ receptors counteracts 5-HT1A regulation of n-methyl-D-aspartate receptor channels in pyramidal neurons of prefrontal cortex. J. Biol. Chem. 283, 17194-17204.

Zhang, Z. W. (2003). Serotonin induces tonic firing in layer $\mathrm{V}$ pyramidal neurons of rat prefrontal cortex during postnatal development. J. Neurosci. 23, 3373-3384.

Zhang, Z. W., and Arsenault, D. (2005) Gain modulation by serotonin in pyramidal neurones of the rat prefrontal cortex. J. Physiol. 566, 379-394.

Zhong, P., Liu, W., Gu, Z., and Yan, Z (2008a). Serotonin facilitates longterm depression induction in prefrontal cortex via p38 MAPK/Rab5mediated enhancement of AMPA receptor internalization. J. Physiol. 586, 4465-4479.

Zhong, P., and Yan, Z. (2011) Differential regulation of the excitability of prefrontal cortical fast-spiking interneurons and pyramidal neurons by serotonin and fluoxetine. PLoS One 6:e16970. doi: 10.1371/journal.pone.0016970

Zhong, P., Yuen, E. Y., and Yan, Z. (2008b). Modulation of neuronal excitability by serotonin-NMDA interactions in prefrontal cortex. Mol. Cell. Neurosci. 38, 290-299.

Zhou, F. M., and Hablitz, J. J. (1999). Activation of serotonin receptors modulates synaptic transmission in rat cerebral cortex. J. Neurophysiol. 82, 2989-2999.

Conflict of Interest Statement: The authors declare that the research was conducted in the absence of any commercial or financial relationships that could be construed as a potential conflict of interest.

Received: 04 February 2012; paper pending published: 28 February 2012; accepted: 28 February 2012; published online: 20 March 2012

Citation: Avesar D and Gulledge AT (2012) Selective serotonergic excitation of callosal projection neurons. Front. Neural Circuits 6:12. doi: 10.3389/fncir. 2012.00012

Copyright (c) 2012 Avesar and Gulledge. This is an open-access article distributed under the terms of the Creative Commons Attribution Non Commercial License, which permits non-commercial use, distribution, and reproduction in other forums, provided the original authors and source are credited. 